\title{
Current trends in removable partial denture teaching in British dental schools
}

IN BRIEF
- Students' removable partial denture
experience, particularly with cobalt-
chromium frameworks, is less than
previously reported.
- Students get very little experience
treating patients requiring a complete
denture in one jaw and a removable
partial denture in the other.
There is concern that removable partial
denture teaching is tailored to the
perceived conditions of the NHS.

Aim To investigate current teaching of removable partial denture construction in British dental schools. Materials and method A questionnaire was sent by email to each of the $15 \mathrm{UK}$ dental schools. Results Replies were received from the 12 long established schools, although one declined to participate. The more recently established schools did not respond. All schools have a pre-clinical/technical course, which either precedes or runs in parallel with the early part of the students' partial denture experience, but students complete very little, if any technical work for their clinical cases. The majority of teaching takes place in multidisciplinary teaching clinics in years 2-5 although the majority of schools concentrate teaching of the basics early in the programme. Fewer cases appear to be treated than previously reported, especially cases requiring removable partial dentures with cobalt chromium frameworks. Students may only treat one such case, the remainder of dentures being constructed of acrylic resin. Lack of experience treating cases requiring a combination of complete and removable partial dentures was a concern. Conclusion Participating schools appear to meet the General Dental Council's requirements. The amount of clinical work undertaken by students may have decreased slightly. There has been a greater decrease in the technical component.

\section{INTRODUCTION}

In The first five years - third edition (interim) $2008^{1}$ the General Dental Council (GDC) states under headings 'Clinical skills' and 'Practical procedures', that new graduates should 'Be competent at designing effective indirect restorations and complete and partial dentures'. Competent is defined by the GDC as meaning 'Students should have a sound knowledge and understanding of the subject together with an adequate clinical experience to be able to resolve clinical problems encountered, independently or without assistance'

A previous investigation into current trends in complete denture teaching in British dental schools ${ }^{2}$ concluded: 'Complete denture courses in British dental schools

\footnotetext{
${ }^{*}$ Emeritus Professor, King's College London, King's College Dental Institute at Guy's King's and St Thomas' Hospitals; ${ }^{2}$ Senior Lecturer/Honorary Consultant, King's College Dental Institute at Guy's King's and St Thomas' Hospitals and University of Portsmouth Dental Academy, Faculty of Science; ${ }^{3}$ Senior Dental Technician, Barts and The London NHS Trust, formally Chief Dental Instructor, King's College Dental Institute, at Guy's King's and St Thomas' Hospitals

*Correspondence to: Professor Robert Clark Email:rkfc@talk21.com
}

\section{Refereed Paper}

Accepted 28 October 2011

DOI: 10.1038/sj.bdj.2011.1003

${ }^{\circledR}$ British Dental Journal 2011; 211: 531-535 vary considerably from good through adequate to barely adequate to inadequate. Some teachers have expressed the view that their students are not adequately prepared for making complete dentures as vocational trainees'. The purpose of this present study therefore was to investigate the current situation with regard to teaching of removable partial denture construction in British dental schools.

\section{MATERIALS AND METHODS}

A questionnaire (Fig. 1) was developed by two experienced teachers of prosthetic dentistry (RKFC and DRR) and piloted on two additional teachers not included in the study but who had experience of curriculum development in prosthodontics. The questionnaire, which was divided into two sections, factual questions and opinion questions, was sent to the persons identified as the senior teacher of prosthetic dentistry in the 12 longer established dental schools, that had been included in the previous complete denture survey, ${ }^{2}$ with a request that they complete it or, if they were not the appropriate person, pass it on to that person. In some instances where a reply was not forthcoming personal contact with another member of the department was employed. Questionnaires were also sent to the three more recently established schools. However, it was more difficult to identify the senior teachers of prosthetic dentistry in the newer schools and so the questionnaires were sent to the deans with a request that they pass them on to the appropriate person.

\section{RESULTS}

Replies were received from all 12 of the longer established schools, one reply of which was a polite refusal to participate. No responses were received from the more recently established schools.

\section{FACTUAL QUESTIONS}

\section{Experience}

Four responding schools commence their removable partial denture teaching in the second year; the remainder start in the third year. In most schools clinical teaching continues in the following years of the programme (Table 1).

In all schools patients requiring removable partial dentures are treated as part of an integrated treatment plan usually by a single student, with the occasional exception when a patient was referred only for 


\section{EDUCATION}

1. During which years of the course do you teach removable partial denture construction?

2. How many removable partial denture patients are your students required to treat?
(a) in a prosthetics clinic
(b) in a multidisciplinary setting

3. How many of the removable partial dentures referred to in answer to Question 2 are made in combination with a complete denture in the opposing jaw?

4. Is there a requirement for your students to treat patients requiring a combination of complete and removable partial dentures?

5. Do your students make removable partial dentures as part of the type of integrated treatment plan commonly referred to as 'whole patient care'? If so,

(a) Is all the treatment of a single patient completed by a single student?

(b) Or does more than one student contribute to the completion of the treatment plan?

Or alternatively, do the students just provide items of treatment as required to fulfil the school's requirements? (The patients required to return to their GDPs for the remaining treatment.)

6. Do you still give clinical demonstrations to students (the students watching a staff member treat a patient) before they start to treat removable partial denture patients themselves? If not how do you introduce students to the clinical stages?

7. Do you have a preclinical/laboratory based/technical removable partial denture course? If so,

(a) does it precede the clinical RPD course or does it run in parallel with it?

(b) And how many sessions is it taught for?

(c) Which of the following does it cover?

Pouring casts

Making custom trays

Blocking out the master cast

Laying down the wax pattern

Setting up teeth

Other technical exercises. Please state.

Surveying the study cast

Surveying the master cast

Duplicating the master cast

Investing and casting

Processing acrylic resin

8. Do your students do any of the technical work for the removable partial dentures they make for patients? If so which of the following stages do they undertake? Pouring casts

Making custom trays

Blocking out the master cast

Laying down the wax pattern

Setting up the teeth

Surveying the study cast

Surveying the master cast

Duplicating the master cast

Investing and casting

Processing acrylic resin

9. What proportion of the removable partial dentures that the students make have cobalt-chromium frameworks?

In the case of the acrylic removable partial dentures

What proportion are tissue borne What proportion are retained by clasps

10. Three strategies are commonly employed in the restoration of free-end (distal extension) saddles, a removable partial denture, shortened dental arch with distally cantilevered bridgework and a shortened dental arch without distally cantilevered bridgework.

Do you teach all three approaches? Can you estimate what proportion are provided with removable partial dentures?

11. In the case of lower free-end (distal extension) saddle removable partial dentures.

(A) Do you teach impression techniques which compensate for the difference in displaceability of the direct abutment and the saddle area? If so, is this
(a) incorporated in the working impression, or
(b) do you teach the use of the altered cast technique?

And if so is this teaching implemented
(a) in theory
(b) in practice

(B) Do you teach the use of RPI/RPA clasping systems on the direct (distal) abutments?

12. How is the competence at removable partial denture provision of your students assessed?
a. continuing assessment
b. non-degree/internal examination
c. degree examination in prosthetic dentistry
e. at risk of being examined as part of final degree exam

13. Are you satisfied that students' competence at removable partial denture construction is adequately examined?

14. Are you satisfied that when your students graduate and become Vocational Trainees, they are adequately prepared to design removable partial dentures and communicate that design to the dental technician?

15. Compared to ten years ago, are your students, when they graduate and enter general practice as Vocational trainees

a. better prepared

c. less well prepared

b. as well prepared

to treat removable partial denture patients? Please can you offer a brief explanation for your answer?

\section{Fig. 1 The questionnaire}

a removable partial denture, or if the treatment was not completed when a student left, in which case another student would continue with the management. Some schools still have a dedicated prosthetics clinic where the students treat patients under the supervision of specialist staff, but in all schools some cases are treated in multidisciplinary restorative clinics.
Experience requirements in terms of cases treated varied among schools (Table 2). Most, who declared a target number, had a requirement of three of which the majority treated one or two in a prosthetics clinic and the rest in a general restorative clinical setting. Three schools had no numerical requirements but gave the following explanations.
'There is no specific clinical requirement but students are advised that by the end of their clinical allocation in 5th year they should have competed at least three RPDs - one cobalt/chrome, one transitional and one lower RPD that opposes a complete upper denture. At least two of these will be completed on "prosthetic clinics" and most will complete 1-2 RPDs 
Table 1 Years during which removable

partial denture teaching occurs. Each

horizontal row represents a responding dental school

\begin{tabular}{|c|c|c|c|}
\hline YEAR 2 & YEAR 3 & YEAR 4 & YEAR 5 \\
\hline & $x$ & & \\
\hline \multirow[t]{2}{*}{$x$} & $x$ & $x$ & $x$ \\
\hline & $x$ & $x$ & $x$ \\
\hline \multirow[t]{3}{*}{$x$} & $x$ & $x$ & \\
\hline & $x$ & $x$ & $x$ \\
\hline & $x$ & $x$ & $x$ \\
\hline \multirow[t]{2}{*}{$x$} & $x$ & $x$ & \\
\hline & $x$ & $x$ & $x$ \\
\hline \multirow[t]{3}{*}{$x$} & $x$ & $x$ & \\
\hline & $x$ & $x$ & $x$ \\
\hline & $x$ & $x$ & $x$ \\
\hline
\end{tabular}

in a multidisciplinary setting though all restorative clinics allow for multidisciplinary treatment.'

'There are no specific requirements beyond the expectation that a range of work will be carried out within the minimum number of seven cases.'

'We do not have specific requirements per se, but that average student attainment will be eight cases by graduation which will include a complete/complete case, an immediate partial denture, and the rest as complete/RPD cases.'

'We do not have targets as we find it unworkable. On average when in the prosthetics clinic they probably treat 3-4 patients. The reason I cannot give you a full answer is that in Year 5 they carry out treatment as part of multidisciplinary care on other clinics.'

The majority of schools have no requirement to treat cases needing an upper complete denture and a lower removable partial denture but most state that their students treat one but some may not.

'Students have to have completed from beginning to end at least one complete denture (ie in one arch), so they get a choice of doing a $C / C$ or $C / P$ or a $C /$ natural teeth. If they do a $C / P$ then this counts as one of their partials. So some students don't ever do a $C / P$.'

'Difficult to say. Depends on the clinical situation. No fixed targets for this, but I guess not many as single arch complete

Table 2 Numbers and quotas of patients treated. Each box represents a responding dental school

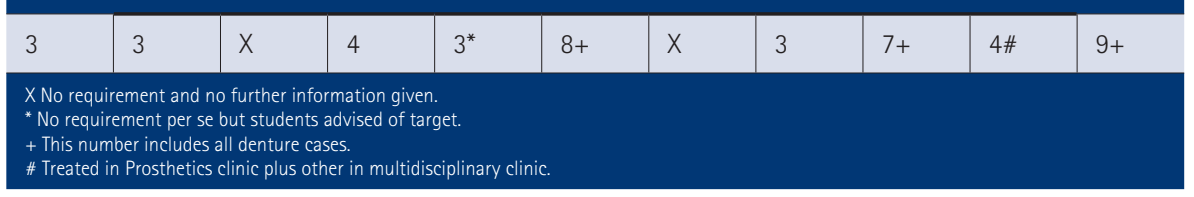

Table 3 Technical laboratory tasks taught to and undertaken by students. Each column represents a responding dental school

\begin{tabular}{|c|c|c|c|c|c|c|c|c|c|c|c|}
\hline Pouring casts & $x$ & $x$ & $x$ & & $x$ & & $x$ & $x$ & $x$ & $x$ & $x$ \\
\hline Surveying the study casts & $x$ & $x$ & $x$ & $x$ & $x$ & $x$ & $x$ & $x$ & $x$ & $x$ & $x$ \\
\hline Making custom trays & $x$ & $x$ & $x$ & $x$ & $x$ & $x$ & $x$ & $x$ & $x$ & $x$ & \\
\hline Surveying the master cast & & $x$ & $x$ & $x$ & $x$ & $x$ & $x$ & $x$ & $x$ & $x$ & $x$ \\
\hline Blocking out the master cast & $x$ & $x$ & $x$ & $x$ & $x$ & $x$ & $x$ & $x$ & & $x$ & $x$ \\
\hline Duplicating the master cast & $x$ & & $x$ & & $x$ & $x$ & $x$ & $x$ & & $x$ & \\
\hline Laying down the wax pattern for $\mathrm{Co}-\mathrm{Cr}$ casting & $x$ & & $x$ & & & $x$ & $x$ & $x$ & $x$ & $x$ & \\
\hline Investing and casting a $\mathrm{Co}-\mathrm{Cr}$ framework & $x$ & & $x$ & & & $x$ & $x$ & $x$ & $x$ & $x$ & \\
\hline Setting up the teeth & $x$ & $x$ & $x$ & $x$ & $x$ & $x$ & $x$ & $x$ & & $x$ & $x$ \\
\hline Processing acrylic resin & $x$ & $x$ & $x$ & $x$ & $x$ & & $x$ & $x$ & & $x$ & $x$ \\
\hline Other (Denture design)* & & $x$ & & & $x$ & & & & & $x$ & $x$ \\
\hline
\end{tabular}

dentures are difficult and often outside the competency of many u/grads. My guess is that about 50\% of students may do one in the dental school and maybe more in outreach (six months with us).'

'There is no specific requirement for a C/P case, so some students don't actually make dentures for such a patient.'

\section{TEACHING}

\section{Preclinical}

Only two schools still give live clinical demonstrations. The remainder use videos together with phantom head and design sessions. All schools have a laboratory based introductory course, which either precedes clinical work (six schools) or runs in parallel (four schools). The length of these laboratory courses varies from seven sessions to 22 whole days, with the majority occupying about 12 sessions. The content of the laboratory courses is summarised in Table 3. Very few schools expect students to do any technical work for the clinical cases that they treat (Table 4).

\section{Clinical}

Of the schools that have requirements, the number of cases treated varied from three to nine (Table 2). In all schools students were expected to treat at least one case requiring a removable partial denture with a cobalt-chromium framework. The remainder of cases consisted of patients requiring acrylic resin removable partial dentures, which were soft tissue supported, although most were provided with clasps. Students do very little of the technical work for the cases they treat in the clinic (Table 4).

All schools teach three strategies for managing free-end (distal extension) saddles, a removable partial denture, or a shortened dental arch with or without distally cantilevered bridgework. Most were not able to estimate the proportion that had removable partial dentures. One respondent indicated about 60\% of patients were restored with lower removable partial dentures. Another reported that most have removable partial dentures.

All schools except one teach impression techniques which allow for the difference in displaceability between the denture bearing mucosa and the direct abutment tooth. All taught ways of achieving this in the working impression and 75\% also taught the altered cast technique. All schools teach the use of RPI/RPA clasping systems for removable partial dentures with free-end saddles. 


\section{Assessment}

All schools examine students' competence in the removable partial denture field although a variety and combination of methods are used other than in two schools (Table 5). One school relied upon continuous assessment alone while two schools relied on a combination of continuous assessment with an internal nondegree examination. One school relied on a non-degree examination alone. In the remainder of schools students faced either being examined in prosthetic dentistry in a section of the final examination or at least being at risk of being examined in finals.

\section{OPINION QUESTIONS}

All but two respondents were satisfied that students were adequately assessed and examined. Seven respondents were satisfied that when they qualified students were adequately prepared to design removable partial dentures and communicate that design to a technician, but two said the students were not equipped and one gave a qualified answer.

A variety of responses were elicited to the question 'Compared to ten years ago, are your students, when they graduate and enter general practice as vocational trainees (a) better prepared (b) as well prepared (c) less well prepared, to treat removable partial denture patients?' While the majority thought their students were as well prepared as ten years ago, one respondent thought the students were better prepared 'They receive more structured teaching.'

Some respondents made interesting comments. 'It is assumed they have less experience (and are possibly less well prepared) than ten years ago because requirements in removable pros have almost halved. So we have taken the approach that QUALITY is important now rather than just QUANTITY of experience, and have tried to keep this in mind when planning the RPD course. We have better teaching facilities now ... ie a skills lab with computer aided teaching aids, and a website for easy access to handouts etc. All of these things seem to help the delivery of teaching. Final years have integrated restorative sessions now (they used not to) which means they manage all aspects of treatment ... not just focusing on one particular discipline at a time, which is regarded as a good thing. Also, students spend time in

Table 4 Technical work undertaken by students for clinical cases. Each column represents a responding dental school

\begin{tabular}{|c|c|c|c|c|c|c|c|}
\hline Pouring the casts & $x$ & $x$ & & & & $x$ & $X^{*}$ \\
\hline Surveying the study cast & $x$ & $x$ & $x$ & $x$ & $x$ & $x$ & $X^{*}$ \\
\hline Making custom trays & & & $x$ & & & $x$ & $\mathrm{X}^{*}$ \\
\hline Surveying the master cast & & $x$ & & & & $\mathrm{x}$ & $\mathrm{X}^{*}$ \\
\hline Blocking out the master cast & & $\mathrm{x}$ & & & & $\mathrm{x}$ & $\mathrm{X}^{*}$ \\
\hline Duplicating the master cast & & & & & & & $\mathrm{X}^{*}$ \\
\hline Laying down the wax pattern & & & & & & & $\mathrm{X}^{*}$ \\
\hline Investing and casting & & & & & & & $\mathrm{X}^{*}$ \\
\hline Setting up the teeth & & $x$ & & & & $x$ & $\mathrm{X}^{*}$ \\
\hline Processing acrylic resin & & & & & & & $X^{*}$ \\
\hline
\end{tabular}

Table 5 Examinations covering prosthetic dentistry. Each column represents a responding dental school

\begin{tabular}{|l|l|l|l|l|l|l|l|l|l|l|l}
\hline Continuing assessment & $\mathrm{X}$ & $\mathrm{X}$ & $\mathrm{X}$ & $\mathrm{X}$ & $\mathrm{X}$ & $\mathrm{X}$ & $\mathrm{X}$ & $\mathrm{X}$ & $\mathrm{X}$ & & $\mathrm{X}$ \\
\hline Non-degree/internal examination & & & $\mathrm{X}$ & & $\mathrm{X}$ & $\mathrm{X}$ & & & $\mathrm{X}$ & $\mathrm{X}$ & $\mathrm{X}$ \\
\hline Degree exam in Prosthetic Dentistry & $\mathrm{X}$ & & & & & & & & & & \\
\hline A section of the Final Examination & $\mathrm{X}$ & & & $\mathrm{X}$ & & & $\mathrm{X}$ & & & & $\mathrm{X}$ \\
\hline At risk of being examined in Finals & $\mathrm{X}$ & & & $\mathrm{X}$ & $\mathrm{X}$ & $\mathrm{X}$ & $\mathrm{X}$ & $\mathrm{X}$ & $\mathrm{X}$ & & \\
\hline
\end{tabular}

Outreach Centres, which adds a great deal to their learning experience. They may not always start and finish the same cases, but they certainly do pros procedures on a wide range of patients which seems to be beneficial.'

'They probably treat fewer patients but have a better understanding. Better prepared academically but not clinically and technically. Massive reduction in RPD clinical experience compared with a 'quota' system used ten years ago. However, I believe from various surveys and student feedback that our undergraduates actually get substantially more clinical experience than at some other UK dental schools.'

'We have developed many online resources - video podcasts of patient treatment, power points etc which have taken the place of chairside dems and enquiries show they receive many "hits" from students, so are accessed. Students have comprehensive technique course and some will do up to nine patient cases by time of graduation.'

'Our RPD course does provide high quality teaching in the theoretical and practical aspects of removable prosthodontics within the clinical skills lab course. The clinical teaching is equally provided to a high standard, although it has to be recognised that the case mix of patients seen by our students are quite often at the high end of clinical needs and equally patient expectations. Many of them being referred in by their GDPs that have been unable to provide the patient with RPDs that are satisfactory (in the patient's view), although it must also be recognised that the current system of NHS remuneration has mitigated against the provision of metal based framework designs, or the provision of multi-procedural stage rehabilitations using multiple crowns and partial dentures by those same NHS GDPs.'

\section{DISCUSSION}

In all schools students are exposed to removable partial denture teaching over several years of the programme, although in one school most of it is concentrated in the third year, with students having relatively little exposure in multidisciplinary clinics. However, the move towards teaching in a multidisciplinary clinical environment while giving the clinical work a broader context does have the disadvantage that less teaching is done by 
specialists, or dentists with a special interest and this difficulty was highlighted by one respondent who stated 'we have just done an audit on this (removable partial denture design) and some staff are as poor as the students in denture design'.

It is perhaps a matter of opinion how many cases a student needs to treat to gain enough knowledge and experience to be fit to qualify and to satisfy General Dental Council requirements. ${ }^{1}$ In a previous study ${ }^{2}$ of current trends in the teaching of complete dentures the authors indicated that there were some programmes which did not provide sufficient complete denture teaching. A previous investigation of removable partial denture teaching, ${ }^{3}$ which also included the Irish dental schools, suggested that the mean number of cobaltchromium and acrylic resin removable partial dentures made by students was three and two respectively. However, this present study has shown that most students may only be making one cobalt-chromium based removable partial denture as those schools that have requirements, state at least one. This present study has shown that students are getting a greater exposure to removable partial denture cases than complete denture cases and while there is an awareness that exposure is not as great as it was in the past, attempts have been made to make up for any clinical short fall with greater academic input. Furthermore the feedback on pre-clinical and technical teaching tends to support the view that an effort is being made to give students a good understanding of the various clinical and technical procedures although unfortunately students no longer benefit from the opportunity to undertake a meaningful amount of the technical work for the patients they treat.

However, a major point of concern is that in many schools the students may not treat more than one patient requiring removable partial dentures with cobaltchromium frameworks. The implications of this are threefold. Firstly, courses in removable prosthodontics appear to be more geared to conditions perceived to exist currently in National Health Service dentistry than an overall understanding of quality and what can be achieved. In the past studies pointed to a difference between the standard of dentistry that was taught and the practicalities of National Health Service practice ${ }^{4}$ but graduates were equipped to do a higher standard of work having had a much more practical training. Secondly, it has been demonstrated that new graduates undergoing vocational training are not well equipped to design removable partial dentures with cobaltchromium frameworks and this has been attributed to inadequate undergraduate teaching. ${ }^{5}$ Thirdly there are considerable and well documented disadvantages of dentures such as those made entirely of acrylic resin because the vast majority are tissue borne and tend to cover much more of the gingival margins, thereby endangering the periodontal tissue, supporting alveolar bone and the abutment tooth structure because of the potential to cause greater plaque accumulation in an already susceptible patient. ${ }^{6}$

However, given that nearly all graduates will at some point work in the National Health Service, certainly during their Foundation Training year, and in their early practising years when they will make a number of acrylic resin based removable partial dentures, it is important that they are taught to make them as well as possible. Reassuringly, the majority of schools reported that their acrylic resin based removable partial dentures were retained with clasps although the survey was unable to elicit any further details of the design principles involved. Interestingly, the British Society for the Study of Prosthetic Dentistry guidelines ${ }^{7,8}$ do not lay down standards for acrylic resin based removable partial dentures but rather seem to assume that all removable partial dentures have metal frameworks.

Another significant point of concern is that many students do not necessarily have experience of treating cases in which an upper complete denture is opposed by a lower removable partial denture. These cases come with a combination of problems as the position of remaining teeth may make designing the occlusion difficult, particularly the lateral occlusions and as a result of tooth loss in one jaw there may be a change, usually a slight reduction, in the resting vertical dimension which will require a similar reduction in the occlusal vertical dimension of the denture, so that inter-arch space may be a problem. ${ }^{9}$ Furthermore, as complete edentulousness becomes less common, patients who are edentulous in only one jaw are becoming a greater proportion of those needing a complete denture and present a significant challenge in practice.

The opinion questions elicited some interesting comments. Reassuringly, most respondents were satisfied that students are as well equipped on graduation as students ten years ago. It was not considered practicable to ask for comparisons with 15 or 20 years ago, and any suggestion that the result would have been different would only be speculative. However, an important difference with what was reported ten years ago seems to be that clinical exposure may in some cases be less but this is compensated for by increased academic and audio-visual input.

\section{CONCLUSIONS}

Within the limitations of this study, all schools that took part in the survey appear to meet the General Dental Council's requirements with regard to provision of removable partial denture teaching. The amount of clinical work undertaken by students may have decreased slightly; the amount of technical work has decreased significantly. The small amount of teaching related to cases requiring a combination of a complete upper denture and a lower removable partial denture and a possible bias towards the perceived standards of the National Health Service are causes of concern.

1. General Dental Council. The first five years The undergraduate curriculum. 3rd edition (interim) report. London: General Dental Council, 2008.

2. Clark R K.F, Radford, D R, Juszczyk A S. Current trends in complete denture teaching in British dental schools. Br Dent J 2010; 208: E10.

3. Lynch C D, Allen P F. The teaching of removable partial dentures in Ireland and the United Kingdom. Br Dent J 2007; 203: E17.

4. Lynch C D. Why do dentists struggle with partial denture design? Br Dent J 2006; 200: 277-281.

5. Barsby, M J, Swartz W D. A survey of the teaching of partial denture construction in dental schools in UK. J Dent 1979; 7: 1-8.

6. Clark R K F. Prevention in prosthodontics. Singapore Dent J 1984; 9: 5-10.

7. The British Society for the Study of Prosthetic Dentistry. Guides to standards in prosthetic dentistry and implant dentistry. London: Quintessence, 1996.

8. The British Society for the Study of Prosthetic Dentistry. Guidelines in prosthetic dentistry and implant dentistry. London: Quintessence, 2005.

9. Nairn, R I, Cuttress T W. Changes in mandibular position following removal of the remaining teeth and insertion of immediate complete dentures. BrDent J 1967; 122: 303-306. 